Original Research Article

\title{
An observational study to assess the knowledge of migraine among patients with migraine at a tertiary care teaching hospital
}

\author{
Rohini Gupta ${ }^{1 *}$, Apporva Malhotra ${ }^{2}$, Pavan Malhotra ${ }^{2}$
}

\begin{abstract}
${ }^{1}$ Department of Pharmacology and Therapeutics, Government Medical College, Jammu, J\&K, India

${ }^{2}$ Department of Pharmacology and Therapeutics, ASCOMS, Sidhra, Jammu, J\&K, India
\end{abstract}

Received: 19 December 2018 Accepted: 29 January 2019

\section{*Correspondence to: \\ Dr. Rohini Gupta, \\ Email: rohinigupta299@ \\ ymail.com}

Copyright: (C) the author(s), publisher and licensee Medip Academy. This is an openaccess article distributed under the terms of the Creative Commons Attribution NonCommercial License, which permits unrestricted noncommercial use, distribution, and reproduction in any medium, provided the original work is properly cited.

\begin{abstract}
Background: Migraine is a common debilitating headache the exact cause of which is not known. Efficient and proper treatment of migraine involves accurate diagnosis, educating the patients and to make them aware of the disorder and finding the best medication for the management of pain. This will also increases the patients' adherence to medication and will help in improving their quality of life. The objective of the study was to assess the awareness of migraine patients towards various aspects of migraine in a tertiary care teaching hospital.

Methods: This was a cross-sectional observational questionnaire-based study conducted from January to March 2017 in ASCOMS\&H, Sidhra, Jammu. The self-administered pre-validated questionnaires pertaining to various aspects of migraine were distributed among the patients diagnosed of having migraine and attending the Neurology Out patient department (OPD). Patients of either sex with a diagnosis of migraine and age $\geq 18$ years were included in the study. The data was analyzed with the help of descriptive statistics.

Results: In the present study, majority of the patients suffering from migraine were in the age group of $18-40$ years $(58.6 \%)$ and females were more commonly affected about $60.9 \%$ than males. There was no family history of migraine in $78.1 \%$ of the patients. About $87.4 \%$ of the patients had 2-6 attacks of migraine per month. The most common triggering factor cited by the patients was lack of sleep in $29.9 \%$ followed by stress in $27.6 \%$ and less water intake in $26.4 \%$ of the patients.

Conclusions: From the present study, it can be concluded that the patients were aware about the associated signs and symptoms but they had inadequate knowledge about all the aspects of the disease. Therefore, it is important to make patients more aware of the disease to increase their compliance to treatment and to improve their quality of life.
\end{abstract}

Keywords: Knowledge, Migraine, Medication adherence, Quality of life, Triggering factors

\section{INTRODUCTION}

Headache is one of the most common central nervous system disorders. It accounts for approx. $25 \%$ of the total outpatient cases seen by the general neurologist. Headache is mainly divided into two types i.e; primary headache and secondary headache. A primary headache is one for which no organic cause can be identified. A secondary headache is associated with organic cause such as brain tumours, aneurysms, stroke and meningitis. ${ }^{1,2}$ Of all the disorders that present to the clinicians with primary headache, migraine is the commonest amongst all. ${ }^{3}$ Migraine is a common debilitating headache affecting $10-15 \%$ of population worldwide, the exact cause of which is not known. Its prevalence ranged from $6 \%$ among males to $18 \%$ among females. ${ }^{4,5}$ The diagnosis of migraine is not so easy to made as it depends upon several criterias. ${ }^{6,7}$ The first step for proper and efficient 
treatment of migraine is accurate diagnosis, educating the patients and to make them aware of the disorder and finding the best medication for the management of pain. ${ }^{8}$ Migraine is characterized by unilateral recurring throbbing headache with moderate to severe in intensity and manifests in attacks lasting for 4-72 hours. ${ }^{9}$ Migraine is generally divided into two types - classical migraine (migraine with aura)which occurs in $15-20 \%$ of the migraine patients and Common migraine (migraine without aura) which occurs in $80-85 \%$ of the migraine sufferers. Classical migraine is preceded by neurological symptoms called aura which can be visual, auditory with or without sensory or motor disturbances. Common migraine is often aggravated by physical work and are accompanied by nausea, vomiting, intolerance to light and sound. ${ }^{10}$ The genetic predisposition with a positive family history of migraine was established in $70-80 \%$ of cases. ${ }^{11}$ Migraine is also more prevalent among females than males. It was established from the previous studies that hormonal changes in females especially during menstrual cycle give rise to gender differences. ${ }^{12,13}$

Migraine was identified as $20^{\text {th }}$ leading cause of years lived with disability (YLD) according to the Global Burden of Disease (GBD) 2000 study. Migraine significantly impairs the Quality of Life (QoL) of an individual as recurrent attacks damage family life, social and professional life to a large extent and even lead to the financial loss of the individual. ${ }^{14}$ Although the exact cause of migraine is not known but it is primarily a vascular disorder and caused by abnormal brain activity. The abnormal brain activity is triggered by many factors. They include: dietary factors, environmental factors, psychological factors, medications, change in habits and many other factors. ${ }^{1}$ Identification and avoidance of triggering factors is very much important in reducing the frequent attacks of headache which constitute the main part of non-pharmacological therapy in the management of migraine. ${ }^{15}$ Other non-pharmacological therapies include the behavioural therapy, stress management, sound sleep, eating nutritious food etc.

Pharmacological treatment includes acute treatment taken at the time of attack to relieve pain and restore function and preventive treatment taken daily to reduce headache frequency. Improving the knowledge regarding the signs and symptoms of the disease, imparting relevant information about the diet and other lifestyle modifications help in prevention of migraine episodes and help thereby in achieving the desired therapeutic outcomes. Thus, it will also help in improving the quality of life of patients. ${ }^{16-21}$ Increasing the awareness about the disease and its triggering factors will also help in managing this disorder effectively as many myths and misunderstandings related to the disease will decrease and the patients' adherence to medication will also increase. Thus, this study was planned to assess the level of knowledge about migraine, its triggering factors and the various signs and symptoms associated with the disease.

\section{METHODS}

This was a cross-sectional observational questionnairebased study conducted from January to March 2017 in Acharaya Shri Chander College of Medical Sciences and Hospital, Sidhra, Jammu, J\&K. The self-administered pre-validated questionnaires were distributed among eighty-seven patients diagnosed of having migraine and attending the Neurology Out Patient department (OPD) of the hospital. Patients of either sex with a diagnosis of migraine and age $\geq 18$ years were included in the study. Patients were explained about the purpose of the study and written informed consent was obtained prior to commencement of the study. The study was approved by the institutional ethical committee. The patients with age less than 18 years and who were not willing to participate in the study and were diagnosed to have other types of secondary headaches like tension headache, cluster headache and other co-morbid conditions were excluded from the study. Also, the patients who were hospitalized with the severe migraine were also excluded from the study.

The questionnaire consists of two parts. First part pertains to the socio-demographic information of the participants which included age, sex, educational status and the marital status of the patients and the second part consists of questions to assess the knowledge of the patients regarding migraine which included family history of migraine, duration of treatment of migraine (years), duration of headache (hrs), type of medication used whether used for the treatment of acute attack or used prophylactically and the associated symptoms and signs of the disease.

The questionnaire also consisted of a checklist to identify the triggering factors of migraine. The triggering factors were recorded for better education and for educating the importance of avoidance of triggering factors. The final duly filled questionnaires were then assessed for the responses of the patients about the various aspects of the migraine.The data was collected and analyzed with the help of descriptive statistics.

\section{RESULTS}

In the present study, majority of the patients suffering from migraine were in the age group of 18-40 years $(58.6 \%)$ and females were more commonly affected about $60.9 \%$ than males and about $79.3 \%$ of the patients were married as shown in Table 1.

Table 2 shows the knowledge assessment of the patients towards migraine. There was no family history of migraine in $78.1 \%$ of the patients. About $49.4 \%$ of the patients had history of migraine from the last five years. About $87.4 \%$ of the patients had 2-6 attacks of migraine per month and about $16.1 \%$ of the patients complained of migraine attack lasting for 48 hours. 
Table 1: Demographic variables of included subjects.

\begin{tabular}{|lll|}
\hline Characteristic & Frequency & Percentage (\%) \\
\hline Age & & \\
\hline $18-40$ & 51 & 58.6 \\
\hline $41-60$ & 27 & 31.0 \\
\hline$>60$ & 9 & 10.3 \\
\hline Sex & & \\
\hline Male & 34 & 39.1 \\
\hline Female & 53 & 60.9 \\
\hline Educational status & & \\
\hline Illiterate & 8 & 9.2 \\
\hline Primary & 21 & 24.1 \\
\hline Secondary & 6 & 6.9 \\
\hline Graduation & 38 & 43.6 \\
\hline Post- Graduation & 14 & 16.1 \\
\hline Marital Status & & \\
\hline Married & 69 & 79.3 \\
\hline Unmarried & 18 & 20.6 \\
\hline
\end{tabular}

Table 2: Knowledge of the patients regarding migraine.

\begin{tabular}{|c|c|c|}
\hline Question & Frequency & Percentage $(\%)$ \\
\hline \multicolumn{3}{|c|}{ Family history of migraine } \\
\hline Yes & 19 & 21.8 \\
\hline No & 68 & 78.1 \\
\hline \multicolumn{3}{|c|}{ Duration of treatment (years) } \\
\hline $0-5$ & 43 & 49.4 \\
\hline $6-10$ & 21 & 24.1 \\
\hline $11-15$ & 13 & 14.9 \\
\hline $16-20$ & 6 & 6.9 \\
\hline$>20$ & 4 & 4.6 \\
\hline \multicolumn{3}{|c|}{ Frequency of migraine attacks (months) } \\
\hline $2-6$ & 76 & 87.4 \\
\hline $7-11$ & 9 & 10.3 \\
\hline $12-16$ & 2 & 2.3 \\
\hline \multicolumn{3}{|c|}{ Duration of headache (hours) } \\
\hline $1-24$ & 61 & 70.1 \\
\hline $25-48$ & 14 & 16.1 \\
\hline $49-72$ & 12 & 13.8 \\
\hline \multicolumn{3}{|c|}{ How often visits doctor for treatment } \\
\hline Monthly once & 28 & 32.2 \\
\hline Three months once & 44 & 50.6 \\
\hline Six months once & 15 & 17.2 \\
\hline \multicolumn{3}{|c|}{ Type of medication used } \\
\hline Acute medication & 46 & 52.8 \\
\hline Preventive medication & 19 & 21.8 \\
\hline Don't know & 22 & 25.3 \\
\hline \multicolumn{3}{|l|}{ Associated symptoms } \\
\hline Nausea & 39 & 44.8 \\
\hline Vomiting & 32 & 36.8 \\
\hline Photophobia & 27 & 31.0 \\
\hline Phonophobia & 17 & 19.5 \\
\hline Blurring of vision & 11 & 12.6 \\
\hline Numbness of hand & 4 & 4.6 \\
\hline Spots in visual field & 3 & 3.5 \\
\hline
\end{tabular}

About $50.6 \%$ of the patients had visited to consult a doctor regarding migraine once in every three months. About $52.8 \%$ of the patients had taken medication for the acute attack of migraine and when the patients were enquired about the associated signs and symptoms majority of the individuals complained about nausea $(44.8 \%)$, vomiting $(36.8 \%)$ followed by photophobia in $31.0 \%$ of the patients as shown in Table 2 .

Table 3 shows the frequency and percentage distribution of triggering factors of migraine. The most common triggering factor cited by the patients was lack of sleep in $29.9 \%$ followed by stress in $27.6 \%$ and less water intake in $26.4 \%$ of the patients.

\section{Table 3: Frequency and percentage distribution of triggering factors of migraine.}

\begin{tabular}{|lll|}
\hline Triggering factors & Frequency & Percentage (\%) \\
\hline $\begin{array}{l}\text { Usage of hormone } \\
\text { replacement }\end{array}$ & 7 & 8.1 \\
\hline $\begin{array}{l}\text { Dairy products e.g. } \\
\text { cheese, butter }\end{array}$ & 21 & 24.1 \\
\hline $\begin{array}{l}\text { Salty foods e.g. } \\
\text { Pickles, chips }\end{array}$ & 11 & 12.6 \\
\hline $\begin{array}{l}\text { Processed or canned } \\
\text { foods }\end{array}$ & 8 & 9.2 \\
\hline $\begin{array}{l}\text { Caffeine intake or } \\
\text { withdrawl }\end{array}$ & 9 & 10.3 \\
\hline $\begin{array}{l}\text { Exposure to excessive } \\
\text { sunlight }\end{array}$ & 13 & 14.9 \\
\hline $\begin{array}{l}\text { Excessive physical } \\
\text { activity }\end{array}$ & 15 & 17.2 \\
\hline Stress & 24 & 27.6 \\
\hline Journey & 6 & 6.9 \\
\hline Less water intake & 23 & 26.4 \\
\hline Alcohol/Smoking & 3 & 3.4 \\
\hline Lack of sleep & 26 & 29.9 \\
\hline Loud sounds & 18 & 20.7 \\
\hline
\end{tabular}

\section{DISCUSSION}

Migraine is one of the common disorders where patients report poor quality of life. ${ }^{22}$ Increased awareness regarding the disease has shown a positive impact on health-care and also a decrease in morbidity and mortality. It has been confirmed from the previous studies that patients' knowledge and awareness has a dramatic effect on medication adherence behavior. ${ }^{23}$ In the present study, females $60.9 \%$ were more commonly affected as compared to males $27.6 \%$. This is consistent with the previously published studies. ${ }^{24}$ The high prevalence in females can be attributed to hormonally driven changes in females. In the present study majority of the patients $58.6 \%$ were in the age group of $18-40$ years. This is consistent with the previously published studies. ${ }^{25}$ This is also consistent with the Global burden of Disease (GBD) 2000 study that the prevalence of migraine is highest during the peak productive years (between the ages 25-55 
years). Also the patients in this age group has more stress and tension that may be responsible for more incidence of headache.

In the present study about $78.1 \%$ of the patients revealed no family history of migraine. About ${ }^{-} 87.6 \%$ of the patients had history of 2-6 attacks per month. About $21.8 \%$ of the patients were taking preventive medications as against $51.8 \%$ who were taking medicines for acute attack. It may be because that most of the patients were not aware of the importance of taking preventive medication. These findings are consistent with the previously published studies. ${ }^{1}$ In the present study, majority of the patients presented with symptoms as nausea in $44.8 \%$ of patients followed by vomiting in $36.8 \%$ and photophobia in $31 \%$ of patients. This is consistent with the previously published studies. ${ }^{9}$ Many a times attacks of migraine are preceded by various symptoms like nausea, vomiting, photophobia etc.

In the present study, when the patients were enquired about the triggering factors, the various factors enumerated by majority of the patients were lack of sleep in $29.9 \%$ of the patients, stress in $27.6 \%$ and less water intake in $26.4 \%$ of the patients. This is consistent with the previously published studies. ${ }^{1}$ The enquiry about the triggering factors help to make patients more aware of the disease and thus it also helps them in making necessary lifestyle modifications and avoidance of the triggering factors. Thus, it can effectively improve the quality of life of patients.

\section{CONCLUSION}

From the present study, it can be concluded that the patients were aware about the associated signs and symptoms but they had inadequate knowledge about all the aspects of the disease. Therefore, it is important to make patients more aware of the disease to increase their compliance to treatment and to improve their quality of life.

Funding: No funding sources

Conflict of interest: None declared

Ethical approval: The study was approved by the Institutional Ethics Committee

\section{REFERENCES}

1. Pavana MN. Assessment of knowledge on migraine and identify the triggering factors among migraine patients at tertiary care centre of Tirupati, Andhrapradesh. J Nursing Health Sci. 2015;4:68-476.

2. Brunner and Suddarth. Textbook of Medical Surgical Nursing: 21st Ed.2. New Delhi: Wolters Kluwer Publication; 2005: 2198-2201.

3. Ravishankar K. Migraine-The New Understanding. Supplement of JAPI. 2010;58:30-3.

4. Steiner TJ, Scher AI, Stewart W, Kolodner K, Liberman J, Lipton RB. The prevalence and disability burden of adult migraine in England and their relationships to age, gender and ethnicity. Int J Headache. 2003;23:519-27.

5. Loder S, Sheikh HU, Loder E. The prevalence, burden and treatment of severe, frequent and migraine headaches in US minority populations: statistics from National Survey studies. Headache. 2015;55:214-28.

6. Lipton RB, Manack Adams A, Buse DC. A comparison of the chronic migraine epidemiology and outcomes (CaMEO) Study. American migraine prevalence and prevention (AMPP) study. Headache. 2016;56:1280-9.

7. Lipton RB, Serrano D, Holland S, Fanning KM, Reed ML, Buse DC, et al. Barriers to the diagnosis and treatment of migraine: effects of sex, income and headache features. Headache. 2013;53:81-92.

8. Silberstein SD. Preventive migraine treatment. Lifelong Learning in Neurology. 2015;21:973-89.

9. Brian KA. Headache. In: Koda-kimble MA, Lioyd YY, Brian KA, Robin LC, Joseph BG, Wayne AK et al. Applied therapeutics. 9th ed. Philadelphia (NY): Lippincott Williams \& Wilkins; 2008: 52.

10. Sharma HL, Sharma KK. Chapter 24: Histamine, Serotonin, Ergot alkaloids and Bradykinin. Section 5: Drug Therapy of Inflammation and Related Autacoids. In: Principles of Pharmacology. 2nd edition. Paras Medical Publisher; 2011: 348-349.

11. Amal KB. Evaluation of headache. J Indian Acad Clin Med. 2005;6(1):17-22

12. Mac Gregor EA. Menstruation, sex hormones and migraine. Neurol Clin. 1997;15:125-41.

13. Silberstein SD, Merriam GR. Sex hormones and headache. In Goadsby PJ, Silberstein SD. Headache. Boston, Butterworth-Heinemann; 1997: 143-176.

14. Lipton RB, Stewart SW. Epidemiology and comorbidity of migraine. In Goadsby PJ, Silberstein SD. Headache. Boston, Butterworth-Heinemann; 1997: 143-176.

15. Negro A, Rocchietti-March, Fiorillo M, Marterlletti P. Chronic Migraine: Current Concepts And Ongoing Treatments. Euro Rev Med Pharma Sci. 2011;15(12):1401-20.

16. Deborah S, Marion RW. Headache disorder. Pharmacotherapy In: Dipiro JT, Talbert RC, Matzke GR, Wells BG, Rosey LM, editors. Pharmacotherapy: A Pathophysiologic Approach. New York: Mc Graw Hill; 2005: 1333-1367.

17. Evers S, Afra J, Frese A, Goadsby PJ, Linde M, May A, et al. EFNS guideline on the drug treatment of migraine - revised report of an EFNS task force. European J Neurol. 2009; 16:968-81.

18. Vaidya PB, Babu SR, Suresh KV. Effectiveness of yoga therapy in the treatment of migraine without aura a randomized controlled trial. Headache. 2007;47(5):654-61.

19. Kaliyaperumal K. Guideline for Conducting a Knowledge, Attitude and Practice (KAP) Study. Community Ophthalmol. 2004;4(1):1-5. 
20. Bozena JK, Steven JK, Stewart JT, Henry HX, Marcelo EB. Adherence to acute migraine medication: What does it mean, Why does it matter? Headache. 2010;50(1):117.

21. Bosworth HB. Medication adherence. In: Bosworth HB. Improving patient treatment adherence: a clinician's guide. New York: Springer Science+Business Media, LLC; 2010: 69-96.

22. John E, Joan AM. The Economic Impact of Migraine: An Analysis of Direct and Indirect Costs. Headache 2002;42:501-9.

23. John FR, Victoria AP, Cheryl S, Kristin K, Naomi SW, Richard M et al. The impact of intensive patient education on clinical outcome in a clinic based migraine population. Headache. 2006;46(5):726-31.
24. Ulku TB, Abdulkadir K. Prevalence and characteristics of migraine in women of reproductive age in Istanbul, Turkey: A population based survey. Tohoku J Exp Med. 2005;206:51-9.

25. Matilde L, Colin M. Global burden of migraine in the year 2000: summary of methods and data source. Global Burden Dis. 2000: 1-15.

Cite this article as: Gupta R, Malhotra A, Malhotra P. An observational study to assess the knowledge of migraine among patients with migraine at a tertiary care teaching hospital. Int J Basic Clin Pharmacol 2019;8:502-6. 